\title{
Prevalence, risk factors and character of abdominal hernia in Arar City, Northern Saudi Arabia in 2017
}

Abdulmajeed AhmedAlenazi ${ }^{1}$, Mahmoud Mohammed Alsharif ${ }^{1}$, Malik Azhar Hussain ${ }^{2}$, Naif Gharbi Alenezi ${ }^{1}$, Abdulrhman Ahmed Alenazi ${ }^{1}$, Shouq Amjad Almadani ${ }^{1}$, Nour Homoud Alanazi ${ }^{1}$, Jazzaa Hammad Alshammari ${ }^{1}$, Alwaleed Oqab Altimyat ${ }^{1}$, Tariq Hulayyil Alanazi ${ }^{1}$

${ }^{1}$ Faculty of Medicine, Northern Border University, Arar, Kingdom of Saudi Arabia

${ }^{2}$ Assistant Professor of Surgery, Northern Border University, Arar, Kingdom of Saudi Arabia

\section{Type of article: Original}

\begin{abstract}
Background: Abdominal wall hernias are a very common surgical condition affecting all ages and both sexes. The main risk factors of hernias include pregnancy, weight lifting, constipation, and weight gain.

Objective: The aim of this study was to determine the prevalence and risk factors of abdominal hernias, their causes, treatment and complications among both sexes of the Arar population (Saudi Arabia).

Methods: A cross-sectional study was conducted among 1,567 adults living in Arar city in 2017. Data was collected by personal interview via questionnaire translated into Arabic, and general and local examination. Data were analyzed by SPSS version 16, using descriptive statistics and Chi Square test.

Results: The overall prevalence of abdominal hernias was $11.7 \%$, hernias were more prevalent in females than in males $(63.4 \%$ vs. $36.6 \%)$, the most common cases were para-umbilical $33.9 \%$, inguinal $27.3 \%$, and umbilical in $20.8 \%$ of the cases, $51.9 \%$ were obese, $53.6 \%$ had previous abdominal surgery, $19.1 \%$ had previous abdominal trauma, $28.4 \%$ had positive family history of hernia and $39.9 \%$ were grand multipara. Hernias were significantly affected by sex, obesity, previous abdominal surgery, previous abdominal trauma, positive family history of hernias and being grand multipara $(\mathrm{p}<0.05)$. Treatment of hernias was surgical in $47.5 \%$ and conservative in $47.0 \%$, complications occurred in $20.2 \%$ and $25.1 \%$ were recurrent after treatment.

Conclusion: Abdominal wall hernias are a common clinical presentation in Arar, KSA. Abdominal hernias are more common in women than men, there is an obvious relationship between obesity and hernias. Early diagnosis, easily accessible health facilities and health education are important to prevent complications. New modality of treatment should be adopted as the standard choice of care to prevent recurrence.
\end{abstract}

Keywords: Abdominal hernia, Prevalence, Risk factor, Arar, Saudi Arabia

\section{Introduction}

Abdominal wall hernias are a very common surgical condition affecting all ages and both sexes. It is an abnormal protrusion of a peritoneal lined sac through the muscular covering of the abdomen (1). The most common symptoms of a hernia include a swelling in the groin, heavy feeling in the abdomen, and discomfort in the abdomen regions, especially when coughing, lifting or bending over. However, symptoms may not appear in some people and they will only realize that they have this condition during medical checkups (2). The hernia can also be characterized as a rupture in smooth tissue through which an organ protrudes or pushes through. It is mainly common in the abdomen, groin regions, navel area and upper thigh. Common types include inguinal, hiatal and umbilical hernias. The most frequent hernia is the inguinal hernia ( $73 \%$ of cases) $(1-4)$. The time a hernia takes to develop depends on its causes, which relate to muscle weakness and strain. Common causes include chronic coughing, damage from an injury or through surgery, and the inability of the wall of the abdomen to close properly (3). The main risk factors of hernia include pregnancy, weight lifting, constipation, and weight gain. The patient should seek medical attention if there is a painful or noticeable bulge on the abdomen, pubic bone or in the groin, or if there are other symptoms of hernia.

\section{Corresponding author:}

Abdulmajeed Ahmed Alenazi, Faculty of Medicine, Northern Border University, Arar, Kingdom of Saudi Arabia. Tel: +966509810608, Email: majeed39@hotmail.com

Received: April 16, 2017, Accepted: May 18, 2017, Published: July 2017

iThenticate screening: May 18, 2017, English editing: June 26, 2017, Quality control: July 03, 2017

(C) 2017 The Authors. This is an open access article under the terms of the Creative Commons Attribution-NonCommercialNoDerivs License, which permits use and distribution in any medium, provided the original work is properly cited, the use is non-commercial and no modifications or adaptations are made. 
The patient can feel the bulge by touching the affected area or notice it when standing upright. It may be possible to push a hernia back into the abdomen, however, this is only possible according to the type of the hernia and the size of the hernia sac content. Abdominal hernias are quite common and are said to occur in no less than two percent of males, although figures from the United States put the estimation at $1.5 \%$ (fifteen cases per thousand) $(1,2)$. Worldwide, it is estimated that more than 20 million hernias are operated on each year (3). Treatment of abdominal hernias may be surgical or non-surgical according to the case and its severity. Some complications can occur after repairing the hernia if the patient did not get sufficient medical care, and it may recur in some cases. A hernia can develop quickly or over a long period of time, depending on its cause. More than 750,000 hernias in the USA and approximately 125,000 hernias in the United Kingdom (UK) are operated on per year (7). The incidence of abdominal wall hernias in different countries varies from $100-300 / 100000$ per year (2). The objective of this study was to determine the prevalence and risk factors of abdominal hernias, their causes, treatment and complications among both sexes of Arar population.

\section{Material and Methods}

\subsection{Research design and sampling}

This cross-sectional study was conducted among 1,567 adults living in Arar city (the capital of the Northern Province of KSA). The data was collected during January and February 2017. The survey was conducted by the Department of General Surgery, Northern Border University, Arar. The study population originally included all male residents aged twenty years or over, residing in Arar. Multistage random sampling was employed to select the study population. Most districts were divided into subdivisions. Each subdivision was again divided into clusters. From those clusters, two were randomly selected. Subjects were selected starting from the reference point (north east corner of selected cluster) employing a simple random sampling technique until the minimum sample size was achieved. The final sample comprised of 1,567 adults.

\subsection{Data collection}

History taking was the first part of data collection and included patient demographics (gender, age, marital status), type of hernia repair undertaken, and whether a primary or recurrent hernia, family history of hernia, type of hernia and the type of treatment of every case, and complications if present. The investigation comprised of an interview at the subject's home and a subsequent examination by a doctor at the department's community health center. Special consideration was paid to standardizing techniques, including the careful training and regulation of interviewers and examiners and the use of standardized questions, examination procedures, and diagnostic criteria. The home interview included a question on the occurrence of hernia, past or present. If it was answered positively, the patient was asked if they had ever had an operation for a hernia. The examining physician was informed of the replies. The examination procedure was the one described by Bailey (1942). The examining physician reported whether, in each groin, there was a visible and clearly palpable hernia; a palpable impulse; or an operation scar. The examination was conducted with the subject standing in a good light. After inspection, any visible lump was palpated to determine whether it was possible to 'get above it' with the thumb and index finger. If not, and if its neck was continuous with the inguinal canal or directed backwards into the abdomen, it was diagnosed as a palpable hernia. If there was no visible lump, the scrotum was invigilated by the little finger to reach the external ring, and the subject was asked to cough, in order to determine whether there was a palpable impulse. An impulse at the scar site on coughing was taken as evidence of recurrence. No attempt was made to distinguish between indirect and direct hernias. 'Swellings' and repaired hernias will be referred to below as 'obvious' hernias. Body weight (in $\mathrm{Kg}$ ) and height was measured for calculation of BMI. Finally, 1,567 questionnaires were filled, the questionnaires were reviewed for completeness and accuracy before data entry.

\subsection{Statistical analysis}

Data were compiled and analyzed using SPSS, version 16 (SPSS Inc., Chicago, Illinois, USA), and results were analyzed with frequencies and Chi square test as appropriate, confidence level and p-value were set at $95 \%$ and $5 \%$, respectively.

\subsection{Ethical considerations}

This study was reviewed for seeking approval of the Research Ethics Committee of the Faculty of Medicine, Northern Border University. Patients were informed that participation was completely voluntary. No name was recorded on the questionnaires. 
http://www.ephysician.ir

\section{Results}

Table 1 illustrates the prevalence of hernias, socio-demographic characteristics and risk factors in the studied population. Only $183(11.7 \%)$ cases from 1,567 screened persons had abdominal hernias, more than $54.2 \%$ of our participants were females, $86.9 \%$ were $18-50$ years old, $55.1 \%$ were married and $41.6 \%$ were single. Regarding body weight, $45.4 \%$ had body weight $60-80 \mathrm{Kg}, 28.9 \% 80-120 \mathrm{Kg}$ and $1.6 \%>120 \mathrm{Kg}$. Previous abdominal surgery was found in $23.9 \%$, only $16 \%$ had a family history of hernias, $7.7 \%$ had previous abdominal trauma and $2.2 \%$ had congenital anomalies. Table 2 shows the relationship between presence of hernia and socio-demographic features and the risk factors in the participants. Hernias were more prevalent in females than males $(63.4 \%$ vs. $36.6 \%)$ and $85.2 \%$ of cases were 18 to 50 years old, $50.8 \%$ had body weight of $60-80 \mathrm{Kg}$ while $13.7 \%$ had less than $60 \mathrm{Kg}$, $51.9 \%$ were obese and $10.9 \%$ of cases did regular exercises. On the other hand (53.6\% vs. 19.9\%) had previous abdominal surgery, (19.1\% vs. 6.1\%) had previous abdominal trauma, $28.4 \%$ had a positive family history of hernias and 39.9\% were grand multipara (repeated pregnancy more than five times). Hernias were significantly affected by sex, obesity, marital status, body weight (in $\mathrm{Kg}$ ), previous abdominal surgery, previous abdominal trauma, positive family history of hernias and being grand multipara $(\mathrm{p}<0.05)$ and were non-significantly affected by age, regular exercise and presence of congenital anomalies $(\mathrm{p}>0.05)$. Table 3 illustrates the character of hernias in the studied cases, we found that; the most common site of abdominal hernias were para-umbilical, as they were found in $33.9 \%$ of cases followed by inguinal in $27.3 \%$ then umbilical in $20.8 \%$. Hernias were non-reducible in $2.7 \%$ of cases. Regarding treatment; surgical in $47.5 \%$ and conservative in $47.0 \%$ and $5.5 \%$ of cases was neglected without TTT. About a quarter $(25.1 \%)$ of hernias were recurrent after treatment and complications were found in $20.2 \%$ of hernias.

Table 1. Prevalence of hernia, socio-demographic characteristics and risk factors in the studied population, Arar, 2017

\begin{tabular}{|c|c|c|c|}
\hline \multicolumn{2}{|l|}{ Parameter } & Frequency $(n=1567)$ & $\%$ \\
\hline \multirow[t]{2}{*}{ Abdominal hernia } & Yes & 183 & 11.7 \\
\hline & No & 1384 & 88.3 \\
\hline \multirow[t]{2}{*}{ Sex } & Male & 717 & 45.8 \\
\hline & Female & 850 & 54.2 \\
\hline \multirow[t]{3}{*}{ Age (year) } & $<18$ & 126 & 8.0 \\
\hline & $18-50$ & 1362 & 86.9 \\
\hline & $>50$ years & 79 & 5.0 \\
\hline \multirow{4}{*}{ Weight (Kg) } & $<60$ & 378 & 24.1 \\
\hline & $60-80$ & 711 & 45.4 \\
\hline & $80-120$ & 453 & 28.9 \\
\hline & $>120$ & 25 & 1.6 \\
\hline \multirow{3}{*}{ Marital status } & Married & 863 & 55.1 \\
\hline & Single & 652 & 41.6 \\
\hline & Divorced or Widowed & 52 & 3.3 \\
\hline \multirow[t]{2}{*}{ Obesity } & Yes & 544 & 34.7 \\
\hline & No & 1023 & 65.3 \\
\hline \multirow[t]{2}{*}{ Regular exercise } & Yes & 202 & 12.9 \\
\hline & No & 1365 & 87.1 \\
\hline \multirow[t]{2}{*}{ Congenital anomalies } & Yes & 34 & 2.2 \\
\hline & No & 1533 & 97.8 \\
\hline \multirow[t]{2}{*}{ Previous abdominal surgery } & Yes & 374 & 23.9 \\
\hline & No & 1193 & 76.1 \\
\hline \multirow[t]{2}{*}{ Previous abdominal trauma } & Yes & 120 & 7.7 \\
\hline & No & 1447 & 92.3 \\
\hline \multirow[t]{2}{*}{ Family history of hernia } & Yes & 250 & 16.0 \\
\hline & No & 1317 & 84.0 \\
\hline \multirow[t]{2}{*}{ Grand multipara (repeated pregnancy) } & Yes & 346 & 22.1 \\
\hline & No & 378 & 24.1 \\
\hline
\end{tabular}


Table 2. Relationship between hernia and socio-demographic features and the risk factors in the studied population, Arar, 2017

\begin{tabular}{|l|l|l|}
\hline Parameter & Chi square & p-value \\
\hline Sex & 6.980 & 0.008 \\
\hline Obesity & 27.035 & 0.00 \\
\hline Marital status & 21.240 & 0.00 \\
\hline Body weight & 13.265 & 0.004 \\
\hline Age & 3.090 & 0.213 \\
\hline Regular exercise & 0.710 & 0.399 \\
\hline Congenital anomalies & 0.00 & 0.987 \\
\hline Previous abdominal surgery & 1.005 & 0.00 \\
\hline Previous abdominal trauma & 38.533 & 0.00 \\
\hline Family history of hernia & 23.995 & 0.00 \\
\hline Grand multipara (repeated pregnancy more than 5 times) & 38.523 & 0.000 \\
\hline
\end{tabular}

Table 3. Character of hernia in studied cases, Arar, 2017

\begin{tabular}{|c|c|c|c|}
\hline \multicolumn{2}{|l|}{ Parameter } & Frequency $(\mathrm{n}=183)$ & $\%$ \\
\hline \multirow{5}{*}{ Site of hernia } & Upper abdomen & 24 & 13.1 \\
\hline & Para-umbilical & 62 & 33.9 \\
\hline & Umbilical & 38 & 20.8 \\
\hline & Inguinal & 50 & 27.3 \\
\hline & Incisional & 9 & 4.9 \\
\hline \multirow[t]{2}{*}{ Size of hernia } & Small & 133 & 72.7 \\
\hline & Moderate or huge size & 50 & 27.3 \\
\hline \multirow[t]{2}{*}{ Reducibility of hernia during presentation } & Non-reducible (stable) & 5 & 2.7 \\
\hline & Reducible & 178 & 97.3 \\
\hline \multirow[t]{3}{*}{ Diagnoses } & By physician & 125 & 68.3 \\
\hline & Self-diagnosis & 37 & 20.2 \\
\hline & Others & 21 & 11.5 \\
\hline \multirow[t]{3}{*}{ Duration of diagnoses } & Within hours & 56 & 30.6 \\
\hline & Days & 43 & 23.5 \\
\hline & Weeks & 84 & 45.9 \\
\hline \multirow[t]{3}{*}{ Type of treatment } & Surgical & 87 & 47.5 \\
\hline & Conservative & 86 & 47.0 \\
\hline & Non-treated & 10 & 5.5 \\
\hline \multirow[t]{3}{*}{ Recurrent after treatment } & Yes & 46 & 25.1 \\
\hline & No & 127 & 69.4 \\
\hline & Not treated & 10 & 5.5 \\
\hline \multirow[t]{2}{*}{ Complication } & Yes & 37 & 20.2 \\
\hline & No & 146 & 79.8 \\
\hline \multirow[t]{4}{*}{ Duration of treatment (day) } & $<7$ & 49 & 26.8 \\
\hline & $7-14$ & 50 & 27.3 \\
\hline & $>14$ & 74 & 40.4 \\
\hline & Not treated & 10 & 5.5 \\
\hline
\end{tabular}

\section{Discussion}

The abdominal hernia is a common condition between both males and females particularly the umbilical and paraumbilical hernia (2). Challenges in surgical practice in developing countries include delayed clinical presentation of patients $(10,14)$ and rather inadequate privately-funded health care financing (16). Our study highlighted the prevalence of hernias, their causes, treatment and complications in Arar city. In the current study, the most common site of abdominal hernias was para-umbilical, as they were found in $33.9 \%$ of cases followed by inguinal $27.3 \%$ then umbilical in $20.8 \%$. The Natalie Dabbas study in the U.K found that, the relative frequency of different hernia types is: inguinal, umbilical, epigastric, incisional, para-umbilical and femoral (8). The following are hernias quoted by various authors, their frequency is in decreasing order: inguinal (70-75\%), femoral (6-7\%), umbilical (3-8.5\%) and 
finally the more uncommon forms of hernia $(1-2 \%)(1,2,5)$. In a study in India (17), lingual hernias had the highest prevalence $(21.8 \%)$ followed by incisional (15.7) and para-umbilical hernias $(13.7 \%)$. The results of this study showed that, hernias were significantly more prevalent in females than in males (63.4\% vs. $36.6 \%)$. Bedewi et al., in a study at King Saud University, Riyadh, Saudi Arabia, found the adult para-umbilical hernia positive cases among females was $24.9 \%$ and that among males was $23.3 \%$ (14). According to the various literature, umbilical and paraumbilical hernias are up to five times more prevalent in women, indicating that pregnancy is a significant etiological influence (5-7). Another study made by Natalie Dabbas in the UK was in complete contrast with this, showing that men in fact underwent more than twice as many umbilical and para-umbilical hernias (8). Our study also found that $51.9 \%$ were obese, $10.9 \%$ of cases did regular exercises and $39.9 \%$ were grand multipara women. Hernias were significantly affected by sex, obesity, body weight (in $\mathrm{Kg}$ ), and being grand multipara $(\mathrm{p}<0.05)$, but there is no significant relationship between doing regular exercise and hernias. A study by Matar at King Khalid Hospital, AlKharj, in Saudi Arabia (12), found obesity was the most common predisposing factor of hernia cases (63\%) and recurrence was more common in the obese patients. These findings were supported by Russell in 2000, who stated that obesity plays an important role as a risk factor for hernias. Increasing BMI and increasing age are associated with a higher prevalence and an increased risk of incarceration of non-inguinal abdominal wall hernias (13). Another factor is that the musculature can be overburdened through increased food intake, as in cases of obesity. Adipose tissue will react to separate muscle bundles and layers, weaken aponeuroses, and can have the appearance of abdominal, hiatus, and direct inguinal hernias (5). Deposition of adipose tissue differs between genders $(9,10)$ and perhaps this contributes to gender differences in hernia formation. Therefore obesity, physical strain and pregnancy are important etiological factors in the development of abdominal hernias. In a study done by Natalie Dabbas in the UK in 2011, the researchers found a relationship between the age of females and accumulation of adipose tissue in the abdomen, as postmenopausal women accumulate more fat in the intra-abdominal depot than do premenopausal women there will be a resultant increase in the number of postmenopausal women who accumulate intra-abdominal adiposity, thereby predisposing to hernia development. Unlike our study in which only $5 \%$ of participants were above 50 years, and only $7.7 \%$ of hernias were above 50 years. More than one fifth $(23.9 \%)$ of our participants represented with previous abdominal surgery, and (53.6\% vs. $19.9 \%)$ of hernia cases had previous abdominal surgery. This relatively high percentage indicates a significant relationship $(\mathrm{P}$ value $<0.05)$ and the previous abdominal surgery acts as a significant risk factor for hernias. These findings are supported by findings from south-western Nigeria (11), which stated that post obstetric and gynecologic surgical interventions ranked highest as the cause of incisional hernias. This could be due to the weakness of the abdominal wall following surgery. In our study, we also found an almost equal percentage $(47.5 \%$ vs. $47.0 \%)$ of surgical and conservative treatment, which was unlike the study carried out in the UK, where treatment through surgery was the most common method. This could be influenced by an increase in the healthcare budget, an increase in day-case operating, or the improved prospect of elective procedure in the elderly. Doctors recommending surgery for earlier, or even asymptomatic hernias, which in the past would otherwise have been deferred until they became symptomatic, could be another possible issue influencing these results. This may be due to new procedures such as laparoscopic surgery, and anesthetic procedures perceived by referrers as less problematic, thus allowing for repair in elderly and higherrisk surgical candidates. An over-all trend towards a decrease in operations carried out on recurrent hernias has been shown. In a study at the King Khalid Hospital in Al-Kharj, Saudi Arabia (12), it was concluded that repairing incisional hernias remains a challenge for the general surgeon, and surgical management should be specialized to each individual patient. Non-recurrence of hernia is a common case in our study (69.4\%), and this may be explained by looking to the means of the development of the hernia treatment. This result agrees with the results of Natalie Dabbas in the UK. (8). In a follow-up study on recurrence after inguinal hernia repair in Saudi Arabia, all the patients were observed for two years after repair, with a total recurrence rate of 2.14 percent (15). In the Matar study, there was recurrence in $4.4 \%$ of cases during a 3 -year follow-up (12). In a study by Langer et al., recurrence was a common complication after repair of large abdominal incisional hernias. Recurrence rates of up to $33 \%$ after first repair and 44\% after second repair have been reported (18).

\section{Conclusions}

Abdominal wall hernias are a common clinical presentation in Arar, KSA. Abdominal hernias are more common in women than in men, there is an obvious relationship between obesity and hernias. Early diagnosis, easily accessible health facilities and health education are important to prevent complications. New modality of treatment should be adopted as the standard choice of care to prevent recurrence. 


\section{Acknowledgments:}

The authors are very grateful to Northern Border University for their continuous support and guidance, and Nagah Mohammed Abo El-fetoh, Reem Sebeh Alhazmi for their help data collection.

\section{Conflict of Interest:}

There is no conflict of interest to be declared.

Authors' contributions:

All authors contributed to this project and article equally. All authors read and approved the final manuscript.

\section{References:}

1) Rains AJH, Capper WM. Bailey \& Love's Short Practice of Surgery. 15th ed. London: Lewis; 1971.

2) Kingnorth A, LeBlanc KA. Management of abdominal hernias. 3rd Edition. London: Edward Arnold, 2003.

3) Kingsnorth A, LeBlanc K. Hernias: inguinal and incisional. Lancet. 2003; 362: 1561-71. doi: 10.1016/S0140-6736(03)14746-0.

4) Townsend C, Beauchamp D, Evers M, Mattox KL, Sabiston DC. Sabiston Textbook of Surgery: The biological basis of modern surgical practice. Philadelphia, PA: WB Saunders, 2001.

5) Russell RCG, Williams NS, Bulstrode CJK. Bailey \& Love's Short Practice of Surgery. 23rd Edition. London: Hodder Arnold; 2000.

6) Williams NS, Bulstrode CJK, O'Connell PR. Bailey \& Love's Short Practice of Surgery. 25th ed. London: Hodder Arnold; 2008. doi: 10.1201/b13454-88.

7) Rutkow IM. Demographic and socioeconomic aspects of hernia repair in United States in 2003. Surg Clin North Am. 2003; 83: 1045-51. doi: 10.1016/S0039-6109(03)00132-4. PMID: 14533902.

8) Dabbas N, Adams K, Pearson K, Royle G. Frequency of abdominal wall hernias: is classical teaching out of date? JRSM Short Rep. 2011; 2(1): 5. doi: 10.1258/shorts.2010.010071. PMID: 21286228, PMCID: PMC3031184.

9) Geer EB, Shen W. Gender differences in insulin resistance, body composition, and energy balance. Gend Med. 2009; 6 Suppl 1: 60-75. doi: 10.1016/j.genm.2009.02.002. PMID: 19318219, PMCID: PMC2908522.

10) Shi H, Clegg DJ. Sex differences in the regulation of body weight. Physiol Behav. 2009; 97: 199-204. doi: 10.1016/j.physbeh.2009.02.017. PMID: 19250944, PMCID: PMC4507503.

11) Adesunkanmi AR, Faleyimu B. Incidence and aetiological factors of incisional hernia in postcaesarean operations in a Nigerian hospital. J Obstet Gynaecol. 2003; 23(3): 258-60. doi: 10.1080/01443610306063. PMID: 12850855.

12) Matar Z. Open Surgical Management of Incisional Hernia. The Internet Journal of Surgery. 2007; 15(2).

13) Lau B, Kim H, Haigh PI, Tejirian T. Obesity increases the odds of acquiring and incarcerating non-inguinal abdominal wall hernias. Am Surg. 2012; 78(10): 1118-21. PMID: 23025954.

14) Bedewi MA, El-Sharkawy MS, Al Boukai AA, Al-Nakshabandi N. Prevalence of adult paraumbilical hernia. Assessment by high-resolution sonography: a hospital-based study. Hernia. 2012; 16(1): 59-62. doi: 10.1007/s10029-011-0863-4. PMID: 21796449.

15) Al-Khuwaiter S. Inguinal hernia in Saudi Arabia. A 10 year experience. Am J Surg. 1985; 149(5): 691-4. doi: 10.1016/S0002-9610(85)80157-4. PMID: 3993855.

16) Sangwan M, Sangwan V, Garg M, Mahendirutta P, Garg U. Abdominal wall hernia in a rural population in India-is spectrum changing? Open Journal of Epidemiology. 2013; 3(3): 135-8. doi: 10.4236/ojepi.2013.33020.

17) Rao G, Rao A, Pujara N, Pujara P, Patel P. Prevalence Of Hernia Among Fishermen Population In Kutch District, India. Natl J Integr Res Med. 2015; 6(4): 44-51.

18) Langer S, Christianseen J. Long-term results after incisional hernia repair. Acta Chir Scand. 1985; 151: 217-9. PMID: 4013599. 